\title{
Effect of preparation based on Paenibacillus ehimensis on the content of alkaloid lappakonitine in harvested rhizomes of Aconitum septentrionale
}

\author{
N.I. Fedorov $\cdot$ Z.A. Ibatullina $\cdot$ O.I. Mikhaylenko $\cdot$ S.N. Zhigunova $\cdot$ G.V. Shendel $\cdot$ L.Y. Kuzmina \\ G.S. Abdrakhimova • A.I. Melentiev • G.R. Kudoyarova
}

Received: 21 May 2018 / Revised: 26 June 2018 / Accepted: 28 June 2018

(C) Korean Society for Plant Biotechnology

\begin{abstract}
We performed an analysis of the effect of postharvest treatment of rhizomes of Aconitum septentrionale Koelle with the biological preparation of Bacispecin based on a cytokinin producing strain of Paenibacillus ehimensis IB-739 on the content of alkaloid lappaconitine in rhizomes. The total alkaloid content was assayed based on exhaustive extraction method. The lappaconitine content was measured by HPLC. The efficiency of the preparation was dependant on either the concentration or intensity of the growth processes in rhizomes. Both parameters varied depending on the stage of development of plants and the amount of precipitation. In the years with normal precipitation, concentrations of Bacispecin ranging from 5 to $10 \mathrm{~g} / 1$ were found to be most effective for increasing lappaconitine content in rhizomes of $A$. septentrionale. Whereas, under local drought conditions, the concentration of preparation should be less than $2 \mathrm{~g} / \mathrm{l}$.
\end{abstract}

Keywords Lappaconitine, Vegetable raw material, Growth stimulators, Paenibacillus ehimensis

\section{Introduction}

Hydro-bromide of alkaloid lappaconitine is the active

N.I. Fedorov $(\varangle) \cdot$ Z.A. Ibatullina $\cdot$ S.N. Zhigunova $\cdot$ G.V. Shendel - L.Y. Kuzmina · A.I. Melentiev1 - G.R. Kudoyarova Ufa Institute of Biology UFRC RAS, 450054, Ufa, Prospekt Oktyabrya, 69

e-mail: fedorov@anrb.ru

O.I. Mikhaylenko

Ufa State Petroleum Technological University, 450062, Ufa, st. Cosmonauts, 1

G.S. Abdrakhimova

Ufa Institute of Chemistry UFRC RAS, 450054, Ufa, Prospekt Oktyabrya, 69 substance of antiarrhythmic drug Allapinin, which is widely used in medical practice. Lappaconitine - diterpenoid alkaloid mainly obtained from the rhizomes of Aconitum septentrionale Koelle. This species is widely spread throughout the Russian territory and its rhizomes are usually harvested at the flowering stage being the most prolonged stage of its seasonal development (Zhigunova et al. 2017). At present production of drugs based on lappaconitine is not provided with the necessary amount of high quality raw material. One of the reasons for this is that interpopulation variability of lappaconitine content in the rhizomes is rather high (from 0.4 to $2.5 \%$ of air-dry mass) during the period of flowering, and, as a result, the harvesting rhizomes at the places of abundant growth of this species is not always profitable (Fedorov et al. 2015). Meanwhile the highest content of alkaloids has been detected during the period of intensification of the growth processes (Fedorov et al. 1996, 2009). This fact suggested possibility of using bacteria capable of promoting plant growth (the so called Plant Growth Promoting Bacteria - PGPB) (Kudoyarova et al. 2015a) for the treatment of freshly harvested rhizomes of $A$. septentrionale.

Paenibacillus ehimensis strain IB-739 being the basis of biological preparation of Bacispecin BM has been shown previously to be capable of synthesis and secretion of plants hormones of cytokinins-type (Arkhipova et al. 2006). Cytokinins are known to be able to influence a range of key processes in the plants including cell division and extension (Downes and Crowell 1998; Ruzicka et al. 2009; Gordon et al. 2009), metabolism of nitrogen and phosphorus (Kudoyarova et al. 2015b), water relations (Davies et al. 2005), initiation and development of vegetative (Gordon et al. 2009) and reproductive organs (Dewitte et al. 1999). The goal of the present work was to study the effect of the treatment of the freshly harvested rhizomes of A. septentrionale with biological preparation based on the strain of 
Paenibacillus ehimensis IB-739 on the content of alkaloid lappaconitine.

\section{Materials and Methods}

The object of research was the rhizomes of Aconitum septentrionale Koelle freshly harvested at the generative phase in the broad-leaved linden forests of the Southern Urals (Ashinskiy district of the Chelyabinsk region) - in a typicical location for this species the association Stachyo sylvaticaeTilietum cordatae.

Experiments were performed during three years, when rhizomes were harvested at the beginning (2016), the middle (2012) and the end (2013) of flowering stage. Stages of flowering differed in the extent of flowers development in the inflorescence. At the beginning of flowering stage partially opened buds were dominating in the middle and upper parts of inflorescence, while at the end of flowering stage both flowers and forming fruits were present. To compare the results obtained in experiments with the maximal values of lappaconitine content in the rhizomes that may be highest during the period of intensive growth at the beginning of the seasonal development and may also increase at the end of growing season, rhizomes were also harvested at the stage prior to flower budding as well as during fruitage. For the microbial treatment of harvested rhizomes, we used the strain of Paenibacillus ehimensis IB-739 deposited in the All-Russian collection of microorganisms at Skryabin Institute of Biochemistry and Physiology of Microorganisms (IBPM RAS) (registration number B-2680D). Biological preparation was used in the form of dry powder obtained by means of spray drying after deep fermentation. Thus the preparation contained alongside with viable spores (titer 2.4 $\times 10^{6} \mathrm{CFU} / \mathrm{g}$ ) all the exo-metabolites including cytokinins undestroyed under conditions of short-term heating. Aqueous suspensions with concentration of preparation 2, 5, 10, 25 and $100 \mathrm{~g} / \mathrm{l}$ were used for the treatment.

Rhizomes were soaked in freshly prepared suspension, placed on trays, covered with polyethylene film to maintain relative air humidity at $85-90 \%$ and kept during 24,72 and 120 hours (5 days) before homogenization and drying. Variant with immediate post harvest homogenization of rhizomes without the treatment with the preparation was used as a control. Thirty rhizomes were used in each variant of treatment.

After the completion of the experiment, rhizomes were homogenized and dried until air-dry state and both total sum of alkaloids and lappaconitine contents in them were assayed. The method of exhaustive extraction was used for measuring the sum of alkaloids in the rhizomes of $A$. septentrionale. Fifty g of homogenized samples were weighed at accuracy to third decimal place. Seventy $\%$ acetone was used as an extragent. Extraction was repeated until complete recovery of alkaloids checked by means of qualitative analysis of tertiary nitrogen with the help of silicotungstic acid. Joined extracts were filtered with Buchner funnel. Acetone was evaporated with rotary evaporator, the residue was acidified with $3 \%$ solution of sulfuric acid to $\mathrm{pH} 2$ and non-alkaloid organic compounds were partitioned into dichlorethan from the aqueous solution.

Aqueous solution containing alkaloids was alkalized to pH 12 with sodium carbonate or $35 \%$ ammonia solution. Then alkaloids were exhaustively partitioned into dichlorethan and dried with the help of anhydrous sodium sulfate. Organic extractant was initially evaporated with the rotary evaporator. The residues were removed under deep vacuum and the sample was churned. The sample brought to constant mass was weighted on analytical balance (Acculab, USA).

The content of lappaconitine in the rhizomes of $A$. septentrionale was assayed by means of HPLC on chromatograph Waters Breeze (Waters Corporation, USA) with double beam spectrophotometer detector. Column Excil Amino $(250 \times 4.6 \mathrm{~mm}, 5 \mu \mathrm{m}$ particle size $)$ was used for analysis. One hundred\% isopropyl alcohol was used as a mobile phase with the flow rate of $1 \mathrm{ml} / \mathrm{min}$. Detection was performed at $254 \mathrm{~nm}$ wave length. In all the cases, mean values were calculated for 3 replicates. The difference between the replicates was less than $2 \%$.

\section{Results and Discussion}

Before considering the effects of the treatment with biological preparation of Bacispecin on the content of lappaconitine in rhizomes of $A$. septentrionale, we shall shortly characterize the complex of factors that might have influenced the content of this alkaloid. The years of sampling differed in temperature and amount of precipitation. Temperature regime in 2016 stood out among other years of experiment conducting. In May and beginning of June in 2016, the weather was cool and the flowering stage beginning occurred two weeks later than usual. However, there were no extreme temperatures during the period prior to experiment conducting, and thereby the temperature was likely to influence only the rate of plant seasonal development.

A more significant effect could be a difference in the amount of precipitation in the period prior the harvesting of rhizomes. In 2013, overall amount of precipitation during 
Table 1 Atmospheric precipitation for 20 days before the initiation of experiments

\begin{tabular}{cccc}
\hline \multirow{2}{*}{ Precipitation } & \multicolumn{3}{c}{ Years of research } \\
\cline { 2 - 4 } & 2012 & 2013 & 2016 \\
\hline Total precipitation (mm) & 52.45 & 20.7 & 51.8 \\
Number of moderate rains* & 2 & 1 & 5 \\
Number of heavy rains** & 3 & - & 1 \\
\hline
\end{tabular}

Notes: ${ }^{*}$ moderate rain $(2.6-8 \mathrm{~mm} / \mathrm{h}) ; * *$ heavy rain $($ more $8 \mathrm{~mm} / \mathrm{h})$

Table 2 The sum of the alkaloid contents and lappaconitine alkaloid in the rhizomes of Aconitum septentrionale after treatment with the preparation of Bacispecin in 2012

\begin{tabular}{|c|c|c|c|c|}
\hline \multirow{2}{*}{$\begin{array}{l}\text { Concentration of } \\
\text { Bacispecin }(g / l)\end{array}$} & \multirow{2}{*}{$\begin{array}{l}\text { Incubation } \\
\text { time }(\mathrm{h})^{* * *}\end{array}$} & \multicolumn{2}{|c|}{ Content in the sample $(\%)$} & \multirow{2}{*}{$\begin{array}{c}\text { Deviation from control } 1 \\
(\%)\end{array}$} \\
\hline & & sum of alkaloids & lappaconitine & \\
\hline \multicolumn{5}{|c|}{ Middle of the flowering stage $\left(12^{\text {th }}\right.$ June 2012) } \\
\hline 2 & 72 & 3.01 & 0.69 & 13.9 \\
\hline 10 & 72 & 3.07 & 0.77 & 26.6 \\
\hline 25 & 72 & 3.08 & 0.66 & 8.4 \\
\hline 100 & 72 & 2.68 & 0.58 & -4.2 \\
\hline Control $1^{*}$ & - & 2.92 & 0.61 & \\
\hline Control $2 * *$ & 72 & 2.91 & 0.62 & \\
\hline
\end{tabular}

Notes: * rhizomes were homogenized immediately after digging out; $* *$ rhizomes were dipped in distilled water; $* * *$ incubation at relative air humidity of $85-90 \%$

20 days prior to sampling was more than two times lower than in 2012 and 2016, and besides, heavy rains were absent, and there was only one moderate rain 10 days before the sampling (Table 1). The rest of precipitation was in the form of weak rains that, in the broad-leaved forests completely retained by the tree canopy and did not influence on the vegetation of shrub and herb layers. Thus we may characterize the 20-days long period preceding the sampling in 2013 as relative drought that might have positive effect on the content of alkaloids in the plants according to some data (Fedorov et al. 1996; Ibatullina et al. 2017).

Alkaloid content in the freshly harvested plant rhizomes might have also been influenced by detachment from the aboveground part and by the loss of most of adventitious roots, as well as by the changes in the temperature during root extraction from the soil. Detachment of the aboveground part may be a cause of a short-term increase in the content of alkaloids in the rhizomes (Fedorov et al. 1997), while an increase in temperature above $25^{\circ} \mathrm{C}$ may decline the alkaloid content in the plant roots (Malik et al. 2013). After extraction of rhizomes of $A$. septentrionale from the soil, their temperature increased up to that of the ambient air that was not significantly different during the sampling of rhizomes (the average daily temperature being from 18.4 to $22.9^{\circ} \mathrm{C}$ ). Proceeding from the abovementioned, it may be considered that the regime of soil hydration was the main factor contributing to the difference between years in alkaloid content in the rhizomes during their sampling at the same habitat.

During a year with typical weather conditions throughout the vegetation period, the content of lappaconitine is the highest at the beginning of the seasonal development, decreases during flowering stage and fruiting and then slightly increases by the end of growing season (Fedorov et al. 1996).

The content of lappaconitine in the control (rhizomes homogenized immediately after digging out) was quite similar at the beginning (2016) and the middle of flowering (2012) (Tables 2 and 4). At the flowering stage in 2013, the content of lappaconitine in the rhizomes was significantly higher that was likely to be due to relative drought (Table 3), since root growth is activated during drought enabling optimization of water uptake (Kudoyarova et al. 2015b).

During the first sampling in 2012, the main criterion of effectiveness of the growth promoting effect of the biological preparation of Bacispecin was in appearance of root buds, massively formed on the third day after the treatment. In connection with this effect, incubation was completed after three days.

Table 2 shows that the resulting content of the sum of 
Table 3 The sum of the alkaloid contents and lappaconitine alkaloid in the rhizomes of Aconitum septentrionale after treatment with the preparation of Bacispecin in 2013

\begin{tabular}{|c|c|c|c|c|}
\hline \multirow{2}{*}{$\begin{array}{l}\text { Concentration of } \\
\text { Bacispecin }(\mathrm{g} / \mathrm{l})\end{array}$} & \multirow{2}{*}{$\begin{array}{l}\text { Incubation } \\
\text { time }(\mathrm{h})^{* *}\end{array}$} & \multicolumn{2}{|c|}{ Content in the sample $(\%)$} & \multirow{2}{*}{$\begin{array}{c}\text { Deviation from control } \\
(\%)\end{array}$} \\
\hline & & sum of alkaloids & lappaconitine & \\
\hline \multicolumn{5}{|c|}{ End of the flowering stage ( $30^{\text {th }}$ June 2013 ) } \\
\hline 2 & 24 & 2.85 & 1.10 & 19.3 \\
\hline 2 & 72 & 3.18 & 0.96 & 3.7 \\
\hline 2 & 120 & 3.01 & 1.09 & 17.5 \\
\hline 10 & 24 & 3.01 & 0.93 & 1.2 \\
\hline 10 & 72 & 3.08 & 0.89 & -3.3 \\
\hline 10 & 120 & 2.81 & 0.99 & 6.9 \\
\hline 25 & 24 & 3.15 & 0.93 & 0.3 \\
\hline 25 & 72 & 3.20 & 0.83 & -10.0 \\
\hline 25 & 120 & 2.89 & 1.00 & 8.0 \\
\hline Control* & & 3.33 & 0.92 & \\
\hline \multicolumn{5}{|c|}{ End of the growing season ( $15^{\text {th }}$ October 2013) } \\
\hline Control* & & 2.19 & 0.78 & \\
\hline
\end{tabular}

Notes: * rhizomes were homogenized immediately after digging out; ** incubation at relative air humidity of $85-90 \%$

Table 4 The sum of the alkaloid contents and lappaconitine alkaloid in the rhizomes of Aconitum septentrionale after treatment with the preparation of Bacispecin in 2016

\begin{tabular}{|c|c|c|c|c|}
\hline \multirow{2}{*}{$\begin{array}{l}\text { Concentration of } \\
\text { Bacispecin }(\mathrm{g} / \mathrm{l})\end{array}$} & \multirow{2}{*}{$\begin{array}{l}\text { Incubation } \\
\text { time }(\mathrm{h})^{* *}\end{array}$} & \multicolumn{2}{|c|}{ Content in the sample (\%) } & \multirow{2}{*}{$\begin{array}{l}\text { Deviation from control } \\
(\%)\end{array}$} \\
\hline & & sum of alkaloids & lappaconitine & \\
\hline \multicolumn{5}{|c|}{ Before the budding stage $\left(17^{\text {th }}\right.$ May 2016) } \\
\hline 10 & 72 & 4.31 & 0.89 & -5.1 \\
\hline Control* & & 4.82 & 0.93 & \\
\hline \multicolumn{5}{|c|}{ Beginning of the flowering stage $\left(13^{\text {th }}\right.$ June 2016$)$} \\
\hline 5 & 24 & 3.52 & 0.86 & 16.2 \\
\hline 5 & 72 & 3.68 & 0.86 & 16.2 \\
\hline 10 & 24 & 3.49 & 0.88 & 18.9 \\
\hline 10 & 72 & 3.68 & 0.83 & 12.2 \\
\hline 25 & 24 & 3.31 & 0.83 & 12.2 \\
\hline 25 & 72 & 3.38 & 0.79 & 6.8 \\
\hline Control* & & 3.20 & 0.74 & \\
\hline \multicolumn{5}{|c|}{ Fruiting stage $\left(02^{\text {nd }}\right.$ August 2016$)$} \\
\hline 10 & 72 & 3.26 & 0.75 & -5.4 \\
\hline Control* & & 3.19 & 0.80 & \\
\hline
\end{tabular}

Notes: * rhizomes were homogenized immediately after digging out, ** incubation at relative air humidity of $85-90 \%$

alkaloids depended on concentration of Bacispecin in solution, where rhizomes have been treated. The initial increase in concentration of Bacispecin resulted in acceleration of the growth processes and in the increase in the content of lappaconitine, but the further rise in concentration of the growth stimulator diminished the effect even down to the level below the control. Thus in 2012 the greatest effect of the treatment with the preparation was detected in the rhizomes harvested in the middle of flowering stage in the case of $10 \mathrm{~g} / 1$ preparation concentration.

In 2016, experiments showed that the same growth promoting effect may be achieved with decline in concentration of Bacispecin down to $5 \mathrm{~g} / \mathrm{l}$ (Table 4).

During local drought of 2013, maximal increase in lappaconitine content was detected in rhizomes treated with lower concentration of Bacispecin ( $2 \mathrm{~g} / \mathrm{l})$, while at $10 \mathrm{~g} / \mathrm{l}$ concen- 
tration the content of lappaconitine did not actually differ from the control (Table 3). It is likely to be connected with the increase in lappaconitine content in the rhizomes in accordance with their accelerated growth detected under moderate drought (Fedorov et al. 2015; Vyroubalova et al. 2009). As result, treatment of rhizomes with cytokinin producing barteria could lead to excessive cytokinin content that failed to enable the growth promoting effect.

Thus during the years characterized by normal precipitation, concentrations of Bacispecin from 5 to $10 \mathrm{~g} / \mathrm{l}$ were the most effective for increasing lappaconitine content in rhizomes of $A$. septentrionale, while under moderate drought the concentration should be decreased to $2 \mathrm{~g} / \mathrm{l}$.

Experiments performed in 2012 suggested that maximal effect of Bacispecin on lappaconitine content in the rhizomes harvested during the flowering stage may not coincide with the time of root buds appearance. In connection with this, we used shorter (24 hours) and longer (5 days) time of incubation following the treatment. Table 4 shows that 24 hours of incubation was sufficient for the increase in lappaconitine content. The content of lappaconitine was higher after 5 days of incubation than after 3 days and at concentration of Bacispecin 10 and $25 \mathrm{~g} / 1$ was even higher than after 1 day of incubation. However after 5 days of incubation root rot appeared on the part of rhizomes showing that the use of this approach in practice may significantly decrease their mass and complicate the procedure of rhizomes cleaning. The increase in lappaconitine content detected after 5-days incubation may be due to the exudates produced during the rot that are likely to have growth stimulating activity.

Bacispecin treatment of rhizomes harvested during stages of development other than flowering stage (flower bud appearance and fruiting) not only did not increase, but even decreased lappaconitine content in the rhizomes (Table 4). During the spring period, this is likely to be due to intensive plant growth, thereby exogenous hormones failed to enable the growth promoting effect. During the period of fruiting, intensive growth processes occur not only in ripening fruits, but also in rhizomes, where intensive formation of the latent buds of the first year renewal and growth of the buds of the second year take place (Serebryakova and Polyntseva 1974).

Thus we revealed the effect of growth promoting preparation of Bacispecin based on cytokinin producing strain of Paenibacillus ehimensis IB-739 on lappaconitine content in the rhizomes of $A$. septentrionale. The degree of the effect depended on the concentration of the preparation and on the intensity of the growth processes that differed depending on the stage of seasonal development and the amount of precipitation. In the years with normal precipitation, concentrations of Bacispecin from 5 to $10 \mathrm{~g} / 1$ were the most effective for increasing lappaconitine content in rhizomes of $A$. septentrionale, while under local drought concentration of preparation should be decreased to $2 \mathrm{~g} / \mathrm{l}$.

\section{Acknowledgements}

The work was financially support by the program of fundamental research of RAS Presidium "Biodiversity of natural ecosystems. Biological resources of Russia: assessment of the state and fundamental basis of monitoring (theme "Development of innovative approaches for management of plant resources for production of drugs on the basis of diterpene alkaloids"). Analyses were carried out with the help of Center for Collective Use of Research Equipment "Agidel".

\section{References}

Arkhipova TN, Veselov SYu, Melentiev AI, Martynenko EV, Kudoyarova GR (2006) Effect of cytokinine-producing microorganisms on plant growth. Biotechnology in Russia (4):66-73

Davies WJ, Kudoyarova G, Hartung W (2005) Long-distance ABA signaling and its relation to other signaling pathways in the detection of soil drying and the mediation of the plant's response to drought. J. Plant Growth Regul. 24(4):285-295

Dewitte W, Chiappetta A, Azmi A, Witters E, Strnad M, Rembur J, Noin M, Chriqui D, Van Onckelen H (1999) Dynamics of cytokinins in apical shoot meristems of a day-neutral tobacco during floral transition and flower formation. Plant Physiol. 119(1):111-122

Downes BP, Crowell DN (1998) Cytokinin regulates the expression of a soybean P-expansin gene by a post- transcriptional mechanism. Plant Mol. Biol. 37:437-444

Fedorov NI, Starukhin FI, Migranova IG, Isangulova AA, Nikitina VS (1997) The effect of mechanical damage to Aconitum septentrionale Koelle plants on the content of diterpene alkaloid lappaconitine in them. Rastitelnye resursy 33(3):62-67

Fedorov NI, Khaziev FK, Gabbasova IM, Suleimanov RR, Zhigunova SN, Lugmanova MR, Mikhailenko OI, Garipov TT (2009) Biological resources of the Southern Urals: Fundamental basics of rational using. Ufa, pp. 58-80

Fedorov NI, Martyanov NA, Nikitina VS, Ishbirdina LM (1996) The content of lappaconitine alkaloid in the underground and aboveground parts of the Aconitum septentrionale Koelle in plant communities in Bashkortostan. Rastitelnye resursy 32(3):96-101

Fedorov NI, Shendel GV, Mikhaylenko OI, Khafizova RR (2015) Interannual variability of the content of lappaconitine in 
rhizomes of Aconitum septentrionale in South Ural. Izvestiya Ufimskogo nauchnogo tsentra RAN 4(1):174-176

Gordon SP, Chickarmane VS, Ohno C, Meyerowitz EM (2009) Multiple feedback loops through cytokinin signaling control stem cell number within the Arabidopsis shoot meristem. Proc. Natl. Acad. Sci. USA 106: 16529-16534

Ibatullina ZA, Shendel GV, Mikhaylenko OI, Abdrakhimova GS, Fedorov NI (2017) Comparison of seasonal dynamics of free amino acids and diterphene alkaloids content in the rhizomes of Aconitum septentrionale in the cis-urals and Southern Urals. Izvestiya Ufimskogo nauchnogo tsentra RAN 3(1):81-85

Kudoyarova GR, Arkhipova TN, Melent'ev AI (2015a) Role of Bacterial Phytohormones in Plant Growth Regulation and Their Development. In: Bacterial methabolites in sustainable agroecosystem. Springer: 69-86

Kudoyarova GR, Dodd IC, Veselov DS, Rothwell SA, Veselov S (2015b) Common and specific responses to availability of mineral nutrients and water. J. Exp. Bot. 66(8):2133-2144

Malik S, Andrade SAL, Sawaya ACHF, Bottcher A, Mazzafera P (2013) Root-zone temperature alters alkaloid synthesis and accumulation in Catharanthus roseus and Nicotiana tabacum. Ind. Crops Prod. 49:318-325

Ruzicka K, Simaskova M, Duclercq J, Petrasek J, Zazimalova E, Simon S, Friml J, van Montagu MC, Benkova E (2009) Cytokinin regulates root meristem activity via modulation of the polar auxin transport. Proc. Natl. Acad. Sci. USA 106: 4284-4289

Serebryakova TI, Polyntseva NA (1974) The rhythm of shoot development and the evolution of life forms in the genus Aconitum L. Bull. MOIP. Otd. Biol. 79 (2):78-98

Vyroubalova S, Vaclavikova K, Tureckova V, Novak O, Smehilova M, Hluska T, Ohnoutkova L, Fmbort I, Galuszka P (2009) Characterization of new maize genes putatively involved in cytokinin metabolism and their expression during osmotic stress in relation to cytokinin levels. Plant Physiol. 151(1): 433-447

Zhigunova SN, Ibatullina ZA, Mikhaylenko OI, Fedorov NI (2017) Stock of Aconitum septentrionale (Ranunculaceae) underground parts in the pine-birch forests and fellings of the Southern Urals. Rastitelnye resursy 53(3):357-371 